Article

\title{
How the Presence of Newly Arrived Migrants Challenges Urban Spaces: Three Perspectives from Recent Literature
}

\author{
Martina Bovo \\ Department of Architecture and Urban Studies, Politecnico di Milano, 20133 Milan, Italy; E-Mail: martina.bovo@polimi.it
}

Submitted: 11 February 2020 | Accepted: 6 April 2020 | Published: 28 July 2020

\begin{abstract}
This article explores the notion of arrival spaces in the recent urban studies literature, and it outlines three emerging perspectives on their role and the associated processes and complexities. Recently, within changing migratory trajectories, the dimension of arrival has gained increasing relevance, and scholars have discussed the growing complexity underpinning it. Within this framework, some contributions reflect on the role of arrival spaces, which currently represent a rapidly changing research subject. However, by the term 'arrival space,' authors refer to various types of space, and the article argues that a clearer reference to the spatial dimension of arrival is needed. Spaces are contexts where different actors interact and intervene in the city, and their understanding represents a preliminary step for future research. In this sense, this contribution aims to unpack the previous decade's debate on arrival spaces. It outlines three main perspectives: The first discusses the role of trans-local contexts, working as nodes in international migration networks; the second follows the debate on arrival neighborhoods; the third suggests that arrival spaces may be defined as all those parts of the urban fabric with which newcomers interact at the moment of arrival. Finally, drawing from this review, the article underlines that arrival spaces are not only specialized areas with migrant newcomers' concentration, but they may also be ordinary urban spaces that temporarily work for arrival. Hence, future research should further deepen this perspective and more explicitly investigate the relation of arrival spaces to the city and its actors.
\end{abstract}

\section{Keywords}

arrival infrastructure; arrival spaces; migration flows; temporariness; urban space

\section{Issue}

This article is part of the issue "Urban Arrival Spaces: Social Co-Existence in Times of Changing Mobilities and Local Diversity" edited by Yvonne Franz (University of Vienna, Austria) and Heike Hanhörster (ILS-Research Institute for Regional and Urban Development, Germany).

(C) 2020 by the author; licensee Cogitatio (Lisbon, Portugal). This article is licensed under a Creative Commons Attribution 4.0 International License (CC BY).

\section{Introduction}

Since the beginning of this century, migration and urban studies research have highlighted the changing nature of migration processes by stressing their diverse geographical patterns (Black, Engbersen, Okólski, \& Panțîru, 2010) and the multiple temporalities (Collins, 2017) and subjectivities (Khosravi, 2010) of migrants. Scholars introduced the concept of 'incomplete' or 'liquid' migration (Black et al., 2010) to describe the complex, transitory, and temporary patterns of contemporary international migratory processes. Along this multifaceted journey, the process of arrival gains relevance. In a context where migration regimes are increasingly imposing le- gal restrictions (Collins, 2011), many scholars outline the extension of arrival in time and space. On a temporal level, arrival is no longer a short step preceding settlement but, in many cases, has turned into a long wait (Bernardie-Tahir \& Schmoll, 2018) that occurs several times along the migratory trajectory. On a spatial level, arrival processes have influenced an increasing number of places, places that have already changed and often in the long-term (Cremaschi, 2016). In addition, building on the work on temporary migration (Collins, 2011, 2017; Vosko, Preston, \& Latham, 2014), scholars have recently begun to focus on the part of the arrival process that is not oriented toward a permanent settlement per se, but rather toward further transit. Arrival is discussed 
as a temporary territorialization (Meeus, Arnaut, \& van Heur, 2018) implying a different use of the social and spatial urban fabric. Within the debate on arrival, many contributions have discussed the role of spaces, and arrival spaces are described as the parts of the urban fabric that play a crucial role for migrants during the arrival process. This concept was already introduced in the early 20th century (Burgess, 1925). However, in the last decade and concerning the changing nature of migration processes, the debate on arrival spaces has gained increasing attention in various disciplines of migration and urban studies. Hence, the theme of arrival spaces is today a very broad and rapidly changing subject of investigation.

However, within this multidisciplinary debate, by the term 'arrival space,' scholars do not refer to a unique type of space, but rather to a range of different contexts. In many cases, space is intended as a background of the arrival process, and its tangible spatial dimension is not always made explicit. Spaces are contexts where different actors interact and intervene in the city, and their understanding represents a preliminary step for future research.

In this sense, the article argues that a clearer definition of the different types of arrival spaces discussed in the literature is needed. The contribution develops a literature review intending to provide an analytical tool to guide future research on arrival spaces and policy challenges. In particular, the article has two sub-objectives: 1) To identify the type of space scholars refer to, and its associated processes and complexities; and 2) to outline the main perspectives on arrival spaces emerging from the recent debate. Thus, the article develops around this initial question: Which spaces matter during migrants' arrival?

The review privileges literature published during the last decade, which refers to recent migration processes and investigates their changing nature and the growing complexity underpinning arrival. Additionally, given the aim of the work, the article explores those contributions that explicitly emplace arrival processes in space. This implies that other relevant aspects, such as legal frameworks, are rather intended as background issues. Urban studies research is taken as the main framework; however, the work also builds on relevant contributions in the field of migration studies, which significantly contributes to the debate, especially since the 'local' and 'spatial turn' (Glick Schiller \& Çağlar, 2015; Scholten, 2014).

With this focus, the article highlights three perspectives on arrival spaces and their features. The first one draws from the discussion on the trans-local character of migratory trajectories and introduces the concept of 'places of condensation' (Bontemps, Makaremi, \& Mazouz, 2018), as those contexts-islands, border towns, major cities-where the local and trans-local nature of migration pathways evidently intersect. The second one assumes the rural-to-urban migration framework and discusses the concept of arrival neighborhoods. The third perspective, by focusing on the complexity of arrival processes, refuses to identify arrival spaces only with specialized urban areas and introduces the notion of more diversified 'arrival infrastructures' (Meeus et al., 2018).

After this introduction to the topic, Section 2 retraces the debate on arrival spaces and its recent developments; Section 3 outlines the three identified perspectives, discussing different types of arrival spaces; finally, the conclusion summarizes the most relevant standpoints, hinting at further trajectories for future research.

\section{The Debate}

The discourse on arrival spaces builds on the extensive literature on the relationship between migratory processes and urban transformations. Today, scholars work in two parallel dimensions: On the one hand, global networks, flows and National policies, and on the other hand, a rather local focus, where municipalities, inhabitants, and local policies act (Caponio \& Borkert, 2010; Filomeno, 2017; Penninx, Kraal, Martiniello, \& Vertovec, 2004; Zapata-Barrero, Caponio, \& Scholten, 2017). A crucial dimension to understand tools and processes of migrants' territorialization appears to be the local one, which looks both at the dynamics occurring in city districts and smaller towns (Briata, 2014; Çağlar \& Glick Schiller, 2018; Caponio, 2006). Urban and migration studies have further built a rich framework around the territorial dimension of migration, focusing on immigrants and populations who are settling-or have already settledin urban areas. Within this long-term perspective, the literature describes the processes of territorialization of immigrants (Blockland \& Savage, 2008) and discusses the tools of spatial policy towards the multiethnic city (Vertovec, 2015).

Within this broad field of research, some scholars focused on the process of arrival and its relation to the urban environment. In this sense, one of the first and more relevant standpoints was represented by the Chicago School of Sociology in the 1920s; through the lens of Social Ecology (Park, Burgess, \& McKenzie, 1925), its scholars developed the concept of 'zones of transition.' Recognizing migration as one of the most relevant drivers of metropolitan development, Burgess (1925) writes a contribution on the growth of the city and describes its expansion as a series of concentric circles, i.e., successive zones of urban extension. Building on the idea of separation and specialization of urban areas, he defines the second concentric circle as a zone of transition with a double role.

On the one hand, these areas are 'ports of first entry' for migrant newcomers and, on the other hand, they fulfill the mentioned transition function towards other neighborhoods (Burgess, 1925). This model has informed urban studies scholars for years, both through critical and supportive standpoints. Many agreed on the specialization of certain urban areas in supporting migrants' arrival and further settlement, and this was one of the starting points for the debate on 'ethnic neighborhoods' and 
the so-called 'context effects' (Hans, Hanhörster, Polívka, \& Beißwenger, 2019).

However, in the discourse on arrival spaces, the main critique of the Chicago School's approach regards the initial standpoint of Social Ecology, an ecology that 'makes' society; as regards arrival neighborhoods, a discussed point is the link between spatial and social mobility. In the recent debate on arrival, many authors argue that spatial mobility is not necessarily linked to social mobility (Hans et al., 2019). Schillebeeckx, Oosterlynck, and de Decker (2018) suggest that the idea of spatial differentiation and specialization, and that of transition are worth retaining, but their spatial logic should rather be explained through political-economic factors. They argue that processes of reciprocity among communities, resources redistribution, and market exchange are the main drivers for the specialization of certain urban areas as transitional zones, experiencing great concentrations of newcomers.

Recently, scholars have underlined the difference between transitional spaces and the so-called ghettos, or destitute places, that is how Burgess (1925) defined the zones of transition. These authors criticize the understanding of the 'context effects' as merely negative and discuss the potentialities underpinning the arrival neighborhoods (Hans et al., 2019). The debate on arrival spaces develops throughout the twentieth century and introduces a rather reciprocal understanding of the relationship between spaces and arrival processes.

Hence, the literature on arrival neighborhoods has characterized the debate on arrival spaces and has represented a main field of investigation in migration and urban studies. This concept is still very much in use; today, many works agree on the criteria of arrival neighborhoods and underline the potentialities lying under these areas (Hans et al., 2019; Kurtenbach, 2015; Meeus et al., 2018; Saunders, 2011; Schillebeeckx et al., 2018). However, concerning the changing patterns of global mobility and migration flows, the reflection on arrival spaces has recently offered new points of view. Many authors reflect on the increasing diversification of arrival spaces (Meeus et al., 2018), their role, and associated processes at different scales. Hence, today the literature provides a rich but fragmented understanding of arrival spaces, which is worth trying to unpack.

\section{Three Complementary Perspectives}

In the debate on arrival processes, this article works on literature published over the last decade, and those authors that more explicitly refer to the spatial dimension of arrival; urban studies literature is taken as mainbut not only-reference. The review identifies three main perspectives, shared by authors across several disciplines. Each perspective privileges a type of arrival space, at different scales: The first one discusses the role of trans-local contexts, working as nodes in international migration networks; the second perspective develops the debate on arrival neighborhoods; the third one introduces the notion of more diversified urban arrival spaces. Additionally, each of these perspectives builds on a shared understanding of some key aspects that are taken as starting points of analysis.

The first aspect of the analysis regards the understanding of arrival: Some scholars focus on arrival as a long-term process (Bressan \& Tosi Cambini, 2011; Saunders, 2011; Schillebeeckx et al., 2018), often leading to permanent settlement; others see it as a temporary situation (Meeus et al., 2018). The second aspect of analysis refers to the type of space that emerges from the different interpretations of arrival; authors identify arrival spaces at different scales and discuss their function during the arrival process. A third aspect of analysis regards the role that the mentioned arrival spaces play in the broader urban context and the challenges that they set for local actors: This subject is not addressed by all reviewed authors, only some of them explicitly reflect on it (Agier et al., 2018; Fawaz, 2016; Hans et al., 2019; Schillebeeckx et al., 2018). The following sub-sections will introduce and discuss the three identified perspectives.

\subsection{Places of Condensation}

London looks back at Calais and Paris looks back at Ventimiglia, Beirut also plays a significant role. (Dahdah \& Puig, 2018, p. 22)

The first perspective draws from recent contributions in the field of anthropology, sociology, and urban planning. This viewpoint on arrival spaces builds on the work of authors who focus on the trans-local nature of contemporary migratory trajectories and the associated complexities. Among them, the review privileges those who reflect on the place-based implications of trans-locality and the consequent definition of arrival spaces. Hence, the work of the research group Babels (Border Analysis and Border Ethnographies in Liminal Situations), and within it, the contributions of Agier (2016), Bernardie-Tahir and Schmoll (2018), Dahdah and Puig (2018), and Bontemps et al. (2018), are taken as key standpoints; for the same reason, the works of Agier et al. (2018) and Cremaschi (2016) represent important references.

Within the broader framework of global mobility, migration flows during the last decade have been increasingly characterized by trans-local territoriality. Each place along the trajectories is strongly interconnected with those preceding and following it. The multilocal emplacement of migrants builds on different factors: Paths are highly variable and strongly interconnected, support networks almost always exceed the limits of the occupied space and relate to global contacts, and, similarly, processes of transnational trades-mainly regarding revenues sent back to countries of origin-are directly linked to migrations (Saunders, 2011).

The circulatory nature of migration paths introduces a renewed understanding of arrival, to be regarded as a 
repeated moment and point along the trajectory, more similar to a series of successive transits, rather than unique destinations (Bontemps et al., 2018). The work of the project Babels (Agier, 2016) is particularly interesting in this sense as it investigates the multilocal nature of recent migrations both theoretically and empirically, through fieldwork in different places around the Mediterranean and in Europe. They define migration as a trajectory made of pathways and moorings, where certain places take on a relevant role, from the points of departure, through those of transit to long-term settlement.

The mentioned viewpoint sheds light on specific contexts, where migrants' arrival occurs at the intersection between trans-local networks and local realities, and where this encounter has dramatic effects on space and society. Bontemps et al. (2018) define these areas as 'places of condensation': local realities where a concentration of multilocal issues and a physical density of events occur, giving them new visibility. Such places are the major arrival cities, but also, some specific threshold regions, such as border towns, which could be considered as truly 'influential places' (Cremaschi, 2016). An example is that of Mediterranean border islands, where the encounter of global processes and local contexts is evident. On a global scale indeed, islands are 'pivots' (Bernardie-Tahir \& Schmoll, 2018) around which trajectories and routes change, according to local, national, and international policies; hence, they work as barriers, transit stops or moorings.

At the same time, beyond the global narrative, local realities undergo dramatic changes. During a lecture in 2019 at the MigBord Summer School, Lesbos, E. Papataxiarchis tells the experience of the small village of Skala (150 inhabitants) in Lesbos, Greece. Since summer 2015, this place has witnessed the passage of 250,000 people, and become the center of global attention; suddenly, the inhabitants of the once-isolated town would find thousands of migrants sleeping in their backyards, international NGOs setting up structures in the town's public spaces, and international magazines reporting the stories of local people.

Similarly, since the late 1980 s, on the Italian island of Lampedusa, the number of migrants passing through the island has exceeded its population by a factor of 80 (Cremaschi, 2017). The effects of this tension have produced changes on many levels. The first is the introduction of new 'players,' which turn certain places into 'battlegrounds' (Fontanari \& Ambrosini, 2018) resulting from power relations of very diverse actors, including migrants. Cremaschi (2017), for instance, outlines the coexistence in Lampedusa of four populations: Inhabitants, tourists, migrants, and practitioners involved in the reception-from medical units to social workers to international press operators. Their presence partially represents a new input for local governance but also implies higher levels of complexity.

On a spatial level, the multilocal nature of migratory pathways outlines the presence and role of 'local places with supralocal meanings'; they may be very different, from the conflictual spaces of refugees' camps to less institutional ones, as public squares, and private backyards. The interplay between the local and supra-local dimension is well expressed by an empirical case discussed by Agier et al. (2018), focusing on the small French town of Grande-Synthe, at the border with the UK. In the backlash of the so-called European 'refugees crisis,' a tent settlement growing at the town's doors reached 5,000 inhabitants; in March 2016, the Mayor decided to intervene and only adopted light measures-i.e., turning the tents into wooden structures-without dismantling nor making the whole site permanent. Initially, the National government had asked to dismantle the camp, arguing that it was unacceptable to allow an 'informal' settlement of that size. However, the town administration understood that what at the local level was an informal settlement also represented a crucial node for the migration trajectory towards the UK. Making the camp and its inhabitants permanent, or dismantling it, would have prevented that space from functioning as a point of temporary arrival and take off.

Despite the effectiveness of the described intervention, this episode describes the challenging role of arrival spaces for the overall urban context. Agier et al. (2018) stress the discomfort of a European town accepting informal settlements, and this point is crucial to understanding the complexity of this arrival space, as discussed below. Informality was somehow granting migrants the possibility for further transit, but at the same time, it was also what made that kind of space 'unacceptable' for that urban context.

The mentioned authors suggest that particular attention should be paid to some specific arrival spaces, as they represent nodes of trans-local networks, but at the same time, different actors have to deal with this condition locally. Consequently, they introduce a further point of view on arrival spaces by suggesting that they are not only relevant within the migratory trajectory, but also concerning the established urban environment and its associated actors. In particular, two main issues arise from the literature review: One related to the actors involved around arrival places of condensation, and a second one referring to the use and organization of the space. As regards the first point, the examples of Lesbos (according to E. Papataxiarchis' lecture) and Lampedusa (Cremaschi, 2017) show how around certain arrival spaces a geography of local and supra-local actors of a different kind is developed: more or less institutional organizations and individuals, professionals, migrants, and local inhabitants. All actors are engaged locally around the arrival space, and their interrelation opens up new scenarios of governance. As regards the relation between arrival spaces and their context, the contributions introduce a second issue. Arrival indeed may imply a new way of using and organizing the space, which may conflict with its more established use. Sometimes this happens only temporarily, when for instance public squares are used for one- 
day protests, however, this may occur also on the longerterm, as in the case of Grande-Synthe's settlement (Agier et al., 2018).

A less regulated, or informal, use and organization of space often characterizes arrival spaces; in many cases, informality is what makes a certain space immediately accessible, and also what allows the transit through it. This clashes with the regulated urban space of many contemporary arrival cities. Cremaschi (2016), referring to the Italian context, writes "given the manner cities are organized, they reject anything that does not fit into procedures" (Cremaschi, 2016, p. 122). In this sense, arrival spaces, when confronted with the urban context also set questions of spatial planning: Which measures should be used to deal with them? Interestingly, these questions often involve areas of the world, such as European arrival cities and destination countries, where informality is less discussed today.

\subsection{Zones of Transition}

The great migration of humans is manifesting itself in the creation of a special kind of urban place. (Saunders, 2011, p. 3)

In recent urban studies literature, a second perspective on arrival spaces can be outlined. It builds on contributions that focus on the urban dimension of arrival, and which consequently emplace the discourse on arrival spaces within the city and its neighborhoods. This literature assumes as background the contribution of the Chicago School of Sociology, and it has recently gained renewed attention. Among academic contributions, the sub-section also mentions the journalistic work of Doug Saunders (2011) in Arrival City: How the Largest Migration in History is Reshaping Our World. The book, far from being a scientific contribution, triggered the debate on arrival spaces and solicited interesting reactions also in the academic realm.

The starting point of many reflections on migration processes is their rural-to-urban trajectory; in other words, migration is seen within the frame of urbanization. Scholars investigate arrival within its urban dimension and position the debate at the level of the city. This, however, does not imply a fixed understanding of it, but rather defines arrival as part of a trajectory that starts in some regions of the world and continues within the city (Saunders, 2011).

Many authors agree on the presence in the city of certain areas that end up playing a crucial role for newcomers, defined as 'zones of transition' (Burgess, 1925). As seen, the definition of these areas changed over the last century. Broadly speaking, they can be described as urban neighborhoods, where the concentration of migrant newcomers corresponds to the specialization of some spaces on arrival and transition. The term 'transition' adequately explains the role of these districts: places with an unstable character that can support ar- rival and mobility within the urban system (Schillebeeckx et al., 2018). The concept was introduced by Burgess (1925) in a contribution to the growth of the city and the notion of arrival neighborhoods still informs the current debate on arrival spaces.

Across current literature, we may identify three main features attributed to arrival neighborhoods. The first one refers to their function as 'ports of first entry' in the city, namely, these areas are the most accessible for newcomers. Saunders (2011) argues that the poor conditions of these districts are what render them accessible and often the only accessible points of the city. He describes it as one of the paradoxes on which the arrival city is built, the logic of the bootstrap, "you cannot possibly afford to live in the city, but to escape being a rural outsider you must first have a place to live in the city" (Saunders, 2011, p. 53).

The second feature of arrival neighborhoods is that of facilitating upward mobility; that is to say that these areas not only provide the first entrance into the city, but also support the transition in time and space through its districts. In this sense, the capacity of certain areas to deploy this function is also what makes them successful or unsuccessful arrival neighborhoods. This argument is not shared by all authors: While Saunders (2011) links social and spatial upward mobility, other authors blame him for being too deterministic (Amin, 2013) and relate this mobility to a series of different factors (Schillebeeckx et al., 2018). In Saunders' narrative, for instance, the case of the Parisian banlieues of Les Pyramides represents a failed arrival city, an 'entrapped' urban transition, where people are stuck between the villages they came from and the French metropolis, that they are never effectively allowed to access (Saunders, 2011). In contrast, Schillebeeckx et al. (2018) ground their definition of Antwerpen-Noord as an urban zone of transition on spatial mobility, not necessarily linked to social and economic improvement. As they write, the neighborhood welcomes $1 / 5$ of the newcomers with foreign roots yearly arriving in the city and the spatial mobility of the neighborhood's residents is the second-highest of Antwerp. However, they also suggest that more research on longitudinal data is needed to understand if the residential mobility corresponds to a socially and economically improved condition (Hans et al., 2019; Schillebeeckx et al., 2018).

The third feature of arrival neighborhoods is introduced in recent contributions and refers to the notion of 'resourcefulness' of these areas (Schillebeeckx et al., 2018): They provide newcomers with a range of resources, that are more accessible than in other parts of the city, and that regard different fields. One of them is access to housing (Günther, Hanhörster, Hans, \& Polívka, 2019), which often deploys through a residual and secondary private rental market. A second aspect that often represents a resource in arrival neighborhoods is the possibility for (self-)employment, often bonded with reciprocal social networks. Where present, welfare services may also represent a key resource field. 
As regards the role of arrival neighborhoods, it is worth reporting a contribution by Fawaz (2016) focusing on the city of Beirut, Lebanon. She discusses the cases of certain areas of the city, that played a crucial role in supporting the first arrival flows of Syrian refugees, starting from 2013. In the years of the so-called 'crisis,' the Lebanese government asked international organizations to propose housing solutions in response to the increasing shelter demand. The only solution to provide the required number of shelters rapidly, they argued, was to establish camps, following what had been already done in other parts of the world. Instead, as Fawaz (2016) underlines, the answer to the housing demand of Syrian refugees was eventually realized in those neighborhoods of the city, where existing networks and low-cost housing conditions enabled an actual emplacement of the newcomers. She further argues that these areas are those presenting the character of informality, and she proposes it as a framework of analysis for these neighborhoods. Accordingly, Fawaz (2016) hints at some specific measures, like the constitution of neighborhood-based organizations, implementation of basic infrastructures, and the involvement of local municipality.

The literature on arrival neighborhoods mainly explores the role of specific urban areas for migrants during the arrival process. In addition, some authors also discuss the relation of these districts to the city and question how they are addressed by local actors. The function of arrival neighborhoods is often grounded in existing networks of local inhabitants, which, in more or less regulated ways, provide easier access to certain resources through secondary housing markets and employment. Their presence and their role in the arrival space open up an issue of governance in many cases. Also, given the largely informal and non-institutional nature of these neighborhoods' resources, the question arises of how public action shall address these areas. In this sense, the authors report tension between the need for heavy interventions and a laissez-faire approach. Schillebeeckx et al. (2018), in the case of Antwerpen-Noord, suggest that public intervention should draw from external resources but also mobilize local knowledge. Interestingly, once more, the debate on arrival neighborhoods shares many similarities with the theme of informality, where a singular regime of rule does not prevail, but rather a fragmented domain of multiple sovereignties (Alsayyad \& Roy, 2006; Darling, 2016). In this sense, we recall the contribution of Fawaz (2016) on Beirut, which bridges the experience of arrival neighborhoods and the planning experience on informality, proposing the latter as a framework of analysis and reflection.

\subsection{Arrival Infrastructures}

We can start envisioning the city and other urban spaces as consisting of more robust platforms for arrival and takeoff. (Meeus et al., 2018, p. 24)
The third perspective draws from contributions that reflect on the diversified nature of arrival processes and, in particular, on their temporary character (Black et al., 2010; Collins, 2011, 2017; Vosko et al., 2014). Among others, the review privileges those scholars that try to relate this concept of arrival to space, thus defining a third perspective on types of arrival space. For this reason, the work on arrival infrastructures by Meeus et al. (2018) represents the main reference.

Migration is experiencing a growing diversification, both as part of global mobility and in itself (Castells, 1996; Tarrius, 1993; Urry, 2007). This increasing complexity is linked to various aspects of the migration process concerning the geography of its patterns, its temporalities, and the growing diversification of people who migrate (Khosravi, 2010).

Contributions reflect on the implications of this process in the definition of arrival; in particular, Meeus et al. (2018) discuss it within three 'politics of arrival,' that of directionality, temporality, and subjectivity. As regards the 'politics of directionality,' drawing from the contributions on transnational studies (Levitt \& Glick Schiller, 2004; Portes, Guarnizo, \& Landolt, 1999), it criticizes the 'one-way directional understanding' of migration, and reflects on its multi-directional nature. By the term 'politics of temporariness,' Meeus et al. (2018, p. 5) argue that "a dichotomy between temporariness and permanence still plays a crucial role in imagining national citizenship rights (permanence) and in the eligibility criteria to obtain these rights (the right to permanence)." This dichotomy hampers a nuanced understanding of processes of arrival, and thus suggest to 'liberate temporariness' (Vosko et al., 2014) and to look at precarious and less precarious forms of arrival.

The 'politics of subjectivity' relates to the diversification of the populations who migrate, which often clashes with the categories used by policies to regulate aim. The definition of the three politics of arrival, according to Meeus et al. (2018), helps to warn of at least two 'traps.' The first is teleological and is well exemplified by the concept of arrival neighborhood. This concept often implies that the migratory path is made of fixed phasesfrom a point of first entry in the city, within a specific neighborhood, to further mobility and settlement-and it prevents from considering the multiplicity of migrants' trajectories. The second 'trap' is defined as territorial: When contextualizing arrival processes in space, it is important to consider all the spaces where they can take place, not only specialized urban areas.

These reflections, shared by many contributions (Papadopoulou-Kourkoula, 2008; Vosko et al., 2014), imply two main shifts in the conceptual understanding of arrival: Firstly, the need to assume a diversified notion of urbanity, namely looking at arrival not only in city neighborhoods, but anywhere it happens. Secondly, the suggestion is to address arrival as a temporary presence and territorialization, not per se oriented towards permanence, even when seeking some kind of stability. It 
follows the need to go beyond the previous perspectives on arrival spaces, and to try to refer to a more dynamic definition, namely moving from the notion of arrival 'city' to that of arrival 'space' (Saeidimadani, 2012).

Starting from here, the focus shifts to 'arrival infrastructures' (Meeus et al., 2018), defined as all those parts of the urban fabric with which newcomers interact at the moment of arrival, through their agencies and competences of use. This term builds on two concepts: the temporariness of arrival and the infrastructural perspective (Blommaert, 2014; Hannam, Sheller, \& Urry, 2006; Simone, 2004). In particular, the concept of infrastructure refers to selective 'channels' that support or prevent mobility, and Meeus et al. (2018) describe arrival infrastructures as both social and material supports, which can be robust or fluid.

Robust infrastructures relate to the material dimension of artifacts and procedures of arrival-citizenship papers, work/residence permit, medical files-, the actors performing them, and the spaces where they take place. Often, such procedures are spatialized in institutions such as police stations, and even more evidently, in detention centers and border crossings. Other robust infrastructures may be the 'institutional settings' (Small, 2009), and what Hans et al. (2019) name 'opportunity structures,' such as community centers and counseling services. They channel the arrival process both by offering low-threshold services and by representing reference and encounter points (Schönwälder et al., 2016). Among robust infrastructures, eventually, we may also include other non-public services, such as money transfer services, which in any case, have a clear spatial dimension.

Fluid infrastructures, instead, are described as emerging from social infrastructuring practices (Werlen, 1992), and involve a rather social dimension. Overall, the concept of arrival infrastructures provides an interesting and new insight into arrival spaces: Many examples of infrastructures indeed correspond to specific spaces. This is clear in the examples of robust infrastructures, but fluid ones often also have a spatial dimension; this is the case of public spaces that have often supported the presence of temporary migrants during arrival. Referring to a contribution by Kleinman (2014), Meeus et al. (2018, pp. 17-18) report:

How West Africans gain access to employment through a social infrastructure in the Gare du Nord station in Paris that partially transforms this space of transportation into a hub of encounter that translates the social infrastructure of African migrants into a French public space.

A further concept that can be related to fluid arrival spaces may be that of 'spatial interstices,' introduced by Fontanari and Ambrosini (2018) around the case of Orianenplatz in Berlin. Here, a group of refugees started a protest against the impossibility to access rights in Germany and based the protest in Orianenplatz square, supported by a wide network of other actors. The square is described, among other non-spatial interstices and 'spaces of struggle,' as a space of opportunity opened by everyday practices and working around imposed structural limits to support the arrival and mobility of newcomers. Hence, by building on the concept of fluid arrival infrastructures, temporary settings might also start to be considered as arrival spaces; this is the case of public spaces that support spontaneous encounters and exchanges among newly arrived migrants. The notion of arrival infrastructures allows thinking of a more diversified range of arrival spaces.

In this third perspective, as in the previous one, the spaces of arrival are described starting from the role that they play for newcomers. However, by building on the reflection on urbanity and temporariness, the literature on arrival infrastructure provides a different viewpoint on arrival spaces. They are not only specialized areas, but they may be any 'ordinary' parts of the urban environment, which for some periods play a relevant role in the process of migrants' arrival. Arrival spaces are not only camps or specific neighborhoods, but can be public squares, libraries, and police stations. In this sense, Meeus et al. (2018) suggest an evocative image of the cities as 'platforms of arrival and take-off,' which temporarily support arrival processes.

Within this framework, further research is needed to discuss who the actors involved in these spaces are and how they act and interact. It is worth underlining that the frame of temporariness opens up a further issue, namely the capacity-and the political will-of cities today to support the temporary presence of migrant populations and the tools that different local actors have to do it. As Collins (2011) suggests, the subject of temporariness still needs further investigation; in this sense, the work on arrival infrastructures appears to be promising perspective to develop, especially through empirical work.

\section{Conclusive Remarks}

Facing the growing diversification of migration processes, many scholars have recently engaged with the topic of arrival. Building on the need to explicitly address its spatial dimension, the article develops a literature review of recent contributions on arrival spaces. To set the stage for future research on the topic, this article has critically reviewed recent works and has outlined three emerging perspectives. The first one refers to so-called 'places of condensation' (Bontemps et al., 2018), which represent pivotal points of arrival within trans-local migratory trajectories. The second perspective discusses the role of arrival spaces within specific urban areas, i.e., arrival neighborhoods. The third understanding describes arrival spaces as ordinary parts of the urban fabric that temporarily work also as arrival spaces.

The three perspectives are complementary, and the related contributions offer common reflections. Firstly, scholars make a shared effort to unpack the complexity 
of arrival, at least on two levels, a territorial and a temporal one. The territorial complexity of arrival lays both in its trans-local (Bernardie-Tahir \& Schmoll, 2018) and local nature, and in the diversification of spaces where it may occur (Meeus et al., 2018). The temporal complexity of arrival builds on its temporariness, which may not necessarily be linked to further settlement; namely, arrival is not per se related to permanence. Secondly, the reviewed contributions agree on some functions of arrival spaces; indeed, although referring to different territorial scales, the three types of arrival spaces do not exclude each other. In the same city, there might be an arrival neighborhood and, at the same time, more fragmented and temporary arrival spaces, this is true both in border regions and in inner areas. In addition, many contributions agree that arrival spaces shall have two main features: be accessible for newcomers and allow further transit. Border islands, arrival neighborhoods, and other urban spaces, at different scales, represent points of first access to the National territory, or to cities. At the same time, these spaces should allow and facilitate the transition to other-and possibly better-spaces within the same territory, or to other parts of the urban environment; in other words, they should facilitate and allow transit. Thirdly, the three perspectives open some shared questions on the role of arrival spaces within the broader urban context. The reviewed literature does not explicitly discuss this point; however, it hints at some recurring questions of governance and planning. Around arrival spaces, we often witness the activation of various actors that introduce the theme of the governance of these areas. At the same time, the organization of these spaces often clashes with the established use of the overall urban context, and this challenges how planning and policy tools may relate to arrival spaces.

Despite the shared issues among the three perspectives, it is worth underling also dissonances. While the literature on arrival neighborhood refers to arrival as a long-term process, the literature on places of condensation and arrival infrastructures consider arrival as a temporary condition-although it can be long-lasting. Indeed, the first tends to refer to arrival as oriented towards permanence, while the latter engage more explicitly with the concept of the temporariness of arrival spaces. The notion of arrival neighborhoods builds on older literature, and it is often influenced by a more linear understanding of arrival; instead, the other perspectives develop around recent migration flows and their circular and temporary character. In this sense, the literature on arrival infrastructures, and the associated understanding of arrival spaces, appears a particularly promising field of investigation. By introducing the concept of 'platforms of arrival and take off,' Meeus et al. (2018) point to new considerations regarding arrival spaces and the city, explicitly related to the temporariness of arrival.

Going back to the initial argument, the three perspectives on arrival spaces show that, under the term 'arrival space,' scholars indeed refer to very different types of spaces, ranging from islands to local police stations and squares. Thus, unpacking this term is a useful step to guide future research on arrival spaces. Additionally, the attempt to outline the different types of spaces mentioned in the literature helps drawing a conclusive remark. The initial question that has been proposed is which are the spaces that matter during arrival? Thus, it assumed the perspective of newcomers and their arrival experience. However, throughout the work, the need to think of how these spaces relate to the urban environment also emerges, as well as how different actors interact with them. This reflection requires a shift in how arrival spaces are viewed: Not only as spaces of migrants' arrival but also as ordinary parts of the city that often have multiple functions.

Recently, scholars have discussed how migrants are rarely addressed as local actors (Çağlar \& Glick Schiller, 2018) and this is even more evident when considering temporary migrants (Collins, 2011). Similarly, arrival spaces are mainly addressed as specialized spaces for arrival, and their role within the overall urban environment and other local actors is less investigated. Border regions and arrival neighborhoods are indeed often discussed as introvert realities; Schillebeeckx et al. (2018) suggest that further research is needed regarding mobility outside the arrival neighborhood.

To conclude, it is worth underlining possible trajectories for future research. Arrival processes, as seen, play a relevant role in the migratory pathway and the city; investigating the spaces where they take place is a needed step to effectively address them. In this perspective, empirical research plays a crucial role, as it implies a place-based work; the mentioned types of arrival spaces may be a starting point for it. In light of the conclusive remarks, research should increasingly address arrival spaces as ordinary and structural parts of cities, and it should explore how actors interact with them. Eventually, this would also allow outlining emerging questions of spatial policy and governance, which this contribution has only hinted at.

\section{Acknowledgments}

The author would like to thank the anonymous reviewers for a highly instructive and insightful set of comments. Thanks also to Prof. Paola Briata, Prof. Massimo Bricocoli, and Prof. Gabriele Pasqui, for the encouragement, commentary, and guidance. All errors remain my own.

\section{Conflict of Interests}

The author declares no conflict of interest.

\section{References}

Agier, M. (2016). Les migrants et nous, comprendre Babel [Migrants and us, understanding Babel]. Paris: CNRS Editions. 
Agier, M., Barré, C., Boccara, D., Esnée, F., Fert, B., Foucher-Dufoix, V., . . Neuman, M. (2018). La ville accueillante: Accueillir à Grande-Synthe questions théoriques et pratiques sur les exilés, l'architecture et la ville [The welcoming city: Welcoming to GrandeSynthe theoretical and practical questions on exiles, architecture and the city]. Paris: PUCA Collection Recherche.

Alsayyad, N., \& Roy, A. (2006). Medieval modernity: On citizenship and urbanism in a global era. Space and Polity, 10, 1-20.

Amin, A. (2013). Telescopic urbanism and the poor. City, 17(4), 476-492.

Bernardie-Tahir, N., \& Schmoll, C. (Eds.). (2018). Méditerranée des frontières à la dérive [Mediterranean borders adrift]. Lyon: Le Passager Clandestin.

Black, R., Engbersen, G., Okólski, M., \& Panțîru, C. (Eds.). (2010). A continent moving West? EU enlargement and labour migration from Central and Eastern Europe (IMISCoe Research Paper). Amsterdam: Amsterdam University Press.

Blockland, T., \& Savage, M. (Eds.). (2008). Networked urbanism. Social capital in the city. Aldershot: Ashgate.

Blommaert, J. (2014). Infrastructures of superdiversity: Conviviality and language in an Antwerp neighborhood. European Journal of Cultural Studies, 17(4), 431-451.

Bontemps, V., Makaremi, C., \& Mazouz, S. (Eds.). (2018). Entre accueil et rejet: Ce que les villes font aux migrants [Between reception and reject: What do cities make to migrants]. Lyon: Le Passager Clandestin.

Bressan, M., \& Tosi Cambini, S. (2011). Zone di transizione. Etnografia urbana nei quartieri e nello spazio pubblico [Zones of transition. Urban ethnography in neighborhoods and in public space]. Bologna: II Mulino.

Briata, P. (2014). Spazio urbano e immigrazione in Italia. Esperienze di pianificazione in una prospettiva Europea [Urban space and immigration in Italy. Planning experiences in a European perspective]. Milan: Franco Angeli.

Burgess, E. W. (1925). The growth of the city: An introduction to a research project. In J. M. Marzluff, E. Shulenberger, W. Endlicher, m. Alberti, G. Bradley, C. Ryan, ... Ute Simon (Eds.), Urban ecology: An International perspective on the interaction between humans and nature (pp. 71-78). Boston, MA: Springer.

Çağlar, A., \& Glick Schiller, N. (2018) Migrants and city making. London: Duke University Press.

Caponio, T. (2006). Città italiane e immigrazione: Discorso pubblico e politiche a Milano, Bologna e Napoli. [Italian cities and immigration: Public discourse and policy in Milan, Bologna and Naples]. Bologna: II Mulino.

Caponio, T., \& Borkert, M. (Eds.). (2010). The local dimension of migration policymaking. Amsterdam: Amsterdam University Press.

Castells, M. (1996). The rise of the network society. The information age: Economy, society and culture. Hoboken, NJ: Blackwell.

Collins, F. (2011). Transnational mobilities and urban spatialities: Notes from the Asia-Pacific. Progress in $\mathrm{Hu}$ man Geography, 36(3), 316-335.

Collins, F. (2017). Desire as a theory for migration studies: Temporality, assemblage and becoming in the narratives of migrants. Journal of Ethnic and Migration Studies, 44(6), 964-980.

Cremaschi, M. (2016). Spazi e "cose" dell'immigrazione [Spaces and "things" of immigration]. Quaderni di Urbanistica 3, 11, 119-125.

Cremaschi, M. (2017). Luoghi e legami: Cosa impariamo da Lampedusa [Places and ties: What do we learn from Lampedusa]. Contesti. Città, Territori, Progetti, 1, 1-16.

Dahdah, A., \& Puig, N. (Eds.). (2018). Exils syriens: Parcours et ancrages (Liban, Turquie, Europe) [Syrian exiles: Paths and moorings (Lebanin, Turkey, Europe)]. Lyon: Le Passager Clandestin.

Darling, J. (2016). Forced migration and the city: Irregularity, informality, and the politics of presence. Progress in Human Geography, 41(2), 178-198.

Fawaz, M. (2016). Planning and the refugee crisis: Informality as a framework of analysis and reflection. Planning Theory, 16(1), 99-115.

Filomeno, F. A. (2017). Theories of local immigration policy. Cham: Palgrave Macmillan.

Fontanari, E., \& Ambrosini, M. (2018). Into the interstices: Everyday practices of refugees and their supporters in Europe's migration "crisis." Sociology, 52(3), 587-603.

Glick Schiller, N., \& Çağlar, A. (2015). Displacement, emplacement and migrant newcomers: Rethinking urban sociabilities within multiscalar power. Identities: Global Studies in Culture and Power, 23(1), 17-34.

Günther, F., Hanhörster, H., Hans, N., \& Polívka, J. (2019). Die Produktion von Ankunftsquartieren Zur Rolle des Wohnungsbestands und seiner Dynamiken für die sozialräumliche Segregation [The production of arrival neighborhoods on the role of the housing stock and its dynamics for socio-spatial segregation]. Düsseldorf: FWG.

Hannam, K., Sheller, M., \& Urry, J. (2006). Editorial: Mobilities, immobilities and moorings. Mobilities, 1(1), $1-22$.

Hans, N., Hanhörster, H., Polívka, J., \& Beißwenger, S. (2019). Die Rolle von Ankunftsräumen für die Integration Zugewanderter. Eine kritische Diskussion des Forschungsstandes [The role of arrival spaces in integrating immigrants. A critical literature review]. Raumforschung und Raumordnung, 77(5), 122-135.

Khosravi, S. (2010). 'Illegal' traveller. An auto-ethnography of borders. London: Palgrave MacMillan.

Kleinman, J. (2014). Adventures in infrastructure: Making an African hub in Paris. City \& Society, 26(3), 286-307.

Kurtenbach, S. (2015). Ankunftsgebiete: Segregation 
als Potenzial nutzen [Arrival neighborhoods: Using segregation as potentiality]. In A. El-Mafaalani, S. Kurtenbach, K. P. Strohmeier (Eds.), Auf die Adresse kommt es an. Segregierte Stadtteile als Problem- und moMglichkeitsräume begreifen [It depends on the address. Comprehending segregated neighborhoods as problem and opportunity] (pp. 306-328). Weinheim and Basel: Beltz Juventa.

Levitt, P., \& Glick Schiller, N. (2004). Conceptualizing simultaneity: A transnational social field perspective on society. International Migration Review, 38(3), 1002-1039.

Meeus, B., Arnaut, K., \& van Heur, B. (Eds.). (2018). Arrival infrastructures: Migration and urban social mobilities. Cham: Palgrave Macmillan.

Papadopoulou-Kourkoula, A. (2008). Transit migration: The missing link between emigration and settlement. New York, NY: Palgrave Macmillan.

Park, R. E., Burgess, E., \& McKenzie, R. D. (1925). The city. Chicago, IL: University of Chicago Press.

Penninx, R., Kraal, K., Martiniello, M., \& Vertovec, S. (2004). Citizenship in European cities. Immigrants, local politics and integration policies. Aldershot: Ashgate.

Portes, A., Guarnizo, L. E., \& Landolt, P. (1999). The study of transnationalism: Pitfalls and promise of an emergent research field. Ethnic and Racial Studies, 22(2), 217-237.

Saeidimadani, M. (2012). Arrival space. Der schmale Grat zwischen Erfolg und Scheitern migrantisch geprägter Räume [Arrival space. The fine line between success and failure of migrant spaces] (Unpublished Master thesis). Politecnico di Milano, Milan, and HCU Hamburg, Hamburg.

Saunders, D. (2011). Arrival city: How the largest migration in history is reshaping our world. London: Windmill Books.

Schillebeeckx, E., Oosterlynck, S., \& de Decker, P. (2018). Migration and the resourceful neighborhood: Explor- ing localized resources in urban zones of transition. In B. Meeus, K. Arnaut, \& B. van Heur (Eds.), Arrival infrastructures: Migration and urban social mobilities (pp. 131-152). Cham: Palgrave Macmillan.

Scholten, P. (2014). The multilevel governance of migrant integration. In B. Garcés-Mascareñas \& R. Penninx (Eds.), Integration processes and policies in Europe (pp 91-108). Berlin: Springer.

Schönwälder, K., Petermann, S., Hüttermann, J., Vertovec, S., Hewstone, M., Stolle, D., . . . Schmitt, T. (2016). Diversity and contact. Immigration and social interaction in German cities. Basingstoke: Palgrave MacMillan.

Simone, A. (2004). People as infrastructure: Intersecting fragments in Johannesburg. Public Culture, 16(3), 407-429.

Small, M. L. (2009). Unanticipated gains. Origins of network inequality in everyday life. New York, NY: Oxford University Press.

Tarrius, A. (1993). Territoires circulatoires et espaces urbains: Différentiation des groupes migrants [Circulatory territories and urban spaces: Differentiation of migrant groups]. Les Annales de la Recherche Urbaine, 59(1), 51-60.

Urry, J. (2007). Mobilities. Cambridge: Polity Press.

Vertovec, S. (Ed.). (2015). Routledge international handbook of diversities studies. London and New York, NY: Routledge.

Vosko, L. F., Preston, V., \& Latham, R. (2014). Liberating temporariness? Migration, work, and citizenship in an age of insecurity. Montreal and Kingston: McGillQueen's University Press.

Werlen, B. (1992). Society, action and space. Abingdon: Taylor \& Francis.

Zapata-Barrero, R., Caponio, T., \& Scholten, P. (2017). Theorizing the 'local turn' in a multi-level governance framework of analysis: A case study in immigrant policies. International Review of Administrative Sciences, 83(2), 241-246.

\section{About the Author}



Martina Bovo is a PhD Candidate in Urban Planning and Policy at DAStU, Politecnico di Milano (Italy). She is currently developing her PhD research on the relationship between migration and places, with particular attention to the dynamics of arrival and 'landing,' as well as to the related spaces and policies. She has been involved in different research projects regarding welfare policies, immigration policies, and services. She has published and presented her work in Italy and abroad. 